\title{
Assessment of a hybrid propulsion system for short-mid range application with a low-order code
}

\author{
Alberto Amerini ${ }^{1}$, Leonardo Langone, Riccardo Vadi, and Antonio Andreini \\ DIEF - Department of Industrial Engineering - University of Florence, via di Santa Marta 3, Firenze
}

\begin{abstract}
The increase in air traffic expected in the next years must be accompanied by innovation to ensure the lowest possible environmental impact. Hybrid electric-thermal propulsion systems are currently being investigated and could represent a breakthrough for environmental sustainability in the sector. However, the transition to electric propulsion remains challenging due to the current level of energy density related to storage systems, the additional components associated with power conversion and control systems, not to mention the cost of all the associated equipment. The purpose of this study is to carry out a preliminary assessment of a hybrid propulsion system for a short-mid range aircraft. This study investigates the series hybrid configuration, where a turboshaft, a high temperature superconducting (HTS) electric motor, batteries and power converters interact to provide the necessary propulsion for flight. A zero-dimensional procedure is developed to estimate the mass and efficiency of the powertrain components for a selected flight mission. Thermal engines are modeled with the low-order code and coupled with the components of the electric system through a python routine. A comparison in terms of weight and emissions is reported for the designed hybrid propulsion system and the conventional one. The analysis shows that the weight of the two propulsion systems is similar but, the presence of batteries, even considering a higher level of technology than the current one, leads to a significant increase in the weight of the hybrid aircraft. The second part of the study focuses on pollutant emissions, showing that the hybrid system can reduce $\mathrm{CO}_{2}$ emissions by $58 \%$ and $\mathrm{NO}_{\mathrm{x}}$ emissions by $68 \%$ compared to the conventional system. Despite the excellent premise, the reduction in payload for the hybrid aircraft causes a reduction in pollutant emissions per passenger only for $\mathrm{NO}_{\mathrm{x}}$. For this reason, further technological improvement is needed to make hybrid propulsion advantageous in terms of both payload and pollutant emissions.
\end{abstract}

\section{Introduction}

In recent years the reduction of polluting emissions has become the main theme of the technological development of propulsion systems, it could not be otherwise given the extremely challenging goals set by ACARE in Flightpath 2050 through which they want to limit emissions of $\mathrm{CO} 2$ by $75 \%$, NOx by $90 \%$ and simultaneous reduction of noise by $80 \%$ [1]. The gap with the technologies currently in use for the combustors system [2] for aeroengine does not seem to be able to have a margin of optimization such as to ensure the

\footnotetext{
1 Corresponding author: alberto.amerini@htc.unifi.it
} 
achievement of the objectives set, for this reason, the scientific community is looking for innovative methodologies for the development of new propulsion systems [3]. The electrification of propulsion systems has become more and more interesting within the avionics sector [4-5]. Zhang et al. [6-7] give an overview of the performance of different electrical machines with high specific power for use in aeronautical applications. The interest in the electrification of aviation transport has continuously grown in recent years due to the performance of new electrical machines capable of working in superconducting conditions even at high temperatures, the HTS motors [8] which provide power densities in line with propulsion applications and efficiencies close to unity, without the complications of operating at cryogenic temperatures.

Over the years, NASA has indicated the main configurations for hybrid and fully electric solutions, and has also proposed various concepts for hybrid propulsion systems [9]. Particularly interesting is the study carried out on the Boeing SUGAR-Volt, the parallel hybrid configuration derived from the SUGAR-Free aircraft with conventional propulsion, in which a $60 \%$ reduction in fuel burned is achieved. However, the authors point out that the increase in weight due to the presence of the additional electrical system results in the same total mission energy consumption and therefore a reduction in $\mathrm{CO}_{2}$ produced over the lifetime of the aircraft is only achieved if the batteries are recharged with renewable energy. Energy storage systems are currently the most critical aspect of the whole electricity chain, the energy density reached by the current technology level is holding back the development of electric propulsion systems. A similar study has been proposed by Wroblewski et al. [10] in which a feasibility study is carried out for a hybrid propulsion system configuration. The authors carry out a parametric analysis as the thrust provided by the electric motor varies for different hybridization sizes, evaluating the reduction in $\mathrm{CO}_{2}$ emissions associated with the reduction in fuel burned. The authors' main conclusions are that a $50 \%$ hybridization level results in a $53 \%$ reduction in $\mathrm{CO}_{2}$ emissions. The modeling of the system was not carried out with the current technological level of battery energy density (around $200 \mathrm{Wh} / \mathrm{kg}$ ) but with a level of $700 \mathrm{wh} / \mathrm{kg}$, which implies an increase in weight of $350 \mathrm{Kg}$. The current battery has an energy density 40 times lower than kerosene [11], which is why purely electric solutions with energy storage are not feasible, as they would lead to an unacceptable reduction in payload. Correct modeling of battery discharge, together with sizing, is essential to make an initial assessment of the weights and dimensions associated with the electrical chain of a hybrid aircraft. In literature, several works deal with this topic, Vratny et al. [12] characterizes batteries for propulsion applications and proposes a methodology to define the sizing of the battery pack according to the flight mission for the Ce-Liner electric aircraft [13-14]. Avanzini et al. [15] show the optimization of the battery pack during a constant-power discharge process as expected in the cruise phase of the flight mission.

In the present article, an initial assessment is made of a series hybrid propulsion system for a regional aircraft, the hybrid system relies on a dedicated electric generator coupled with a turboshaft. Both the modeling aspects of the conventional engine, onboard generator, and the electrical chain are examined. The input parameters of the model for the electrical side are obtained through detailed modeling of the conventional propulsive system. Once the methodology used has been described, the aspects related to the weights of the proposed solution will be assessed and the pollutant emissions analyzed. With respect to the works present in the literature, in addition to $\mathrm{CO} 2$ emissions, a correlative estimation of $\mathrm{NOx}$ emissions is carried out.

\section{Methodology}

The mentioned hybrid propulsive system has been investigated with a low-order numerical approach, aiming to evaluate its performances robustly and cost-effectively. Each component 
is modeled with a simplified description representative of the physics involved. Since the additional complexity introduced by the electrical system, in the following the numerical modeling of each sub-system and the mutual integration is reported.

\subsection{Hybrid Propulsive system}

In this section, the investigated hybrid-series configuration is described considering the integration among all its components. The system consists of the turboshaft connected to the generator, whose task is to convert mechanical energy into electrical energy required by the system. In this configuration, there are power converters to allow integration of the batteries and drive the electric motor. The latter component is to convert electrical energy into mechanical one and transmit the power to the fan mounted on the drive shaft. The system replaces a single conventional engine and a sketch of the concept is reported in Figure 1 (the figure is only intended to show the connection of the individual components and has no bearing on the location in the airframe). Figure 1 shows the energy flows and efficiencies of the two main power lines at cruise phase: the one from the generator to the electric motor $\left(\eta_{\text {turb } \rightarrow m o t}\right)$ and the one from the battery to the electric motor $\left(\eta_{\text {batt } \rightarrow \text { mot }}\right)$; the two definitions, as well as the trend of the two efficiencies, are reported in the section dedicated to results.

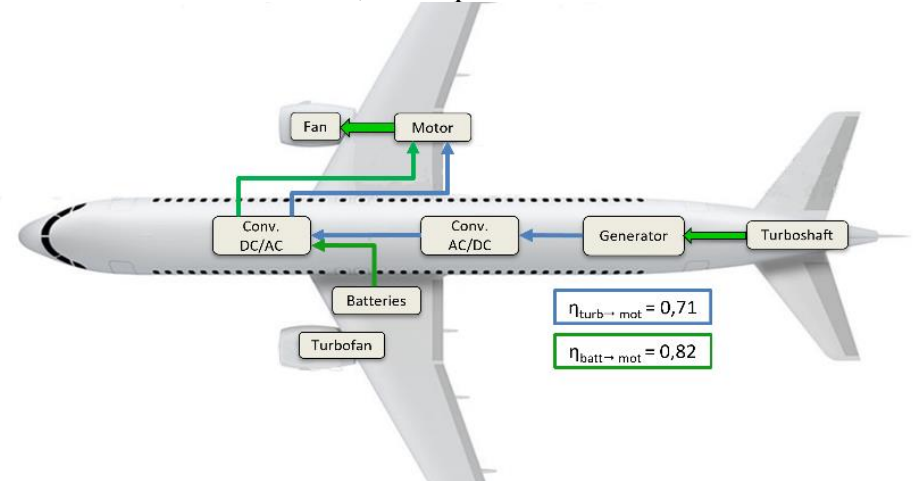

Fig. 1. Diagram of the series hybrid configuration with electric line efficiencies at cruise phase.

Aiming to simplify the modeling strategy, two assumptions are made: the turboshaft works exclusively during the cruise phase providing constant power and the thrust is provided exclusively by the bypass flow in the hybrid propulsion system. This means that the concern involved uniquely the power supplied to the fan to produce the thrust without considering the contribution from the expansion of the combustion exhaust. Once the turbomachines are simulated, the necessary quantities are derived to design the electrical subsystem: to this aim, a further python routine is employed as shown in Figure 2.

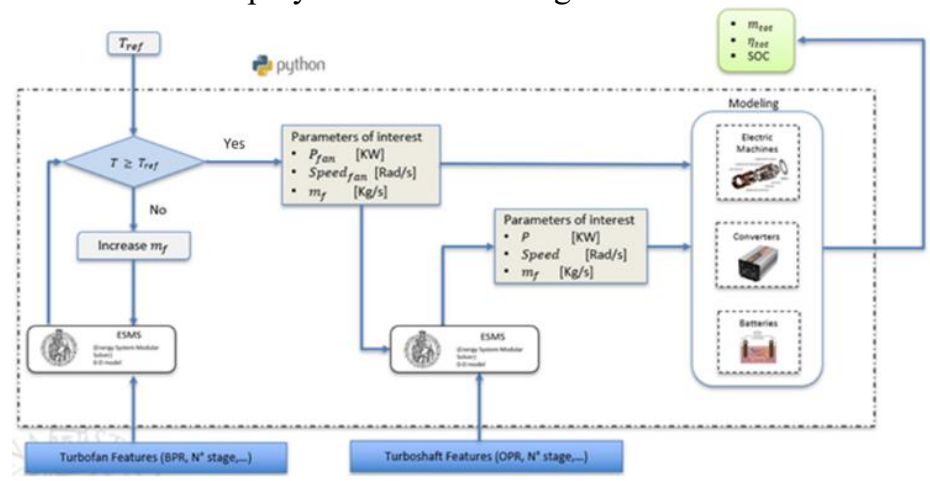

Fig. 2. Flow chart of the implementation procedure. 
Starting from the simulation of the conventional configuration, the values of the power supply and the number of revolutions of the fan, other than the fuel consumption are determined during the whole flight mission. Then, the power at the cruise is evaluated to complete the turboshaft modeling: as for the conventional thermal engine, the power, the number of revolutions, and the fuel used by the turboshaft are obtained. These parameters are used to model the line components. The mission starts with a fully charged battery (state of charge $\mathrm{SOC}=1$ ) and that will satisfy the entire energy demand during the Take-Off, Climb-Out, and Approach phases. At Cruise, propulsion will be provided by both the battery and the turboshaft. In this way the turboshaft works at the design point, providing constant work. Furthermore, it is assumed that the component is working at full capacity from the beginning, without considering a start-up or shut-down phase.

\subsection{Thermal engine modeling}

Conventional engines and the auxiliary power unit for battery charging are based on gas turbines. To model these systems and the related components, the ESMS (Energy Solver Modular System) modular code [16] is used. This code has been largely employed in previous works in literature [17-18] concerning both industrial plants and aircraft engines. It employs a $0 \mathrm{D}$ approach, where the main flow parameters are evaluated by solving iteratively a set of non-linear equations, representative of the whole engine. ESMS performs firstly a simulation of the Design point, where the nominal performances and the geometry of the machine are carried out. Therefore, Off-Design simulations are possible for estimating the performances when the operating conditions differ from the Design point, that is the usual scenario of an aircraft through its flight mission.

The conventional engine model exploits the technical data available from the manufacturer for the main components of the engine (e.g., overall pressure ratio, bypass ratio, number of stages, etc.). Any input not present in the literature is assumed according to similar engines or derived with a try and error procedure within the validation strategy. The Design point for this propulsive system is considered at Cruise conditions, at which the larger part of the flight mission takes place. The validation of such numerical model has been conducted considering the LTO cycle [19] related to the specific engine: the flight phases regulated by this cycle are considered as Off-Design conditions. This means that by imposing the fuel flows for each condition according to the values reported in [19] for the specific engine, the same reference thrust is retrieved. Differently, the turbo-shaft employed in the hybrid system has been validated considering the power output according to the manufacturer specifics at Sea Level conditions [20].

\subsection{Electrical devices modeling}

\subsubsection{Electrical machines}

The electrical machines are described starting from a permanent magnet synchronous motors (PSMS) model and varying the parameters to take account of HTS technology, in particular, the replacement of classical coils with HTS coils. The geometry is estimated using the Pyrohnen [21] and Rucker [22] methods, considering the design parameters available in the literature for the specific application. Also, generators and motors can be considered equally from a structural point of view. The estimation requires the value of the maximum number of revolutions $n_{\max }$ and power demand at design point $P_{\text {des }}$ : such values are defined by the maximum power and number of revolutions of the low-pressure shaft during the flight mission concerning the electric engine. Instead, the design parameters of the generator are 
defined by the power and revolutions of the turboshaft. For the sake of brevity, the complete expressions concerning all the geometric features estimation are left to [23]. Once the volume of each motor component has been estimated, the mass is calculated using the physical properties of the corresponding material, as follows:

$$
M_{\text {tot }}=\sum_{i} \rho_{i} \cdot A_{i} \cdot L_{i}
$$

Where $\rho_{i}$ denotes the assumed density of the i-th component, while $A_{i}$ and $L_{i}$ are respectively its cross-sectional area and its length once calculated according to [23]. The influence on the weight of a cooling system of the HTS is neglected in this preliminary study. The efficiency of these devices is assumed to be high and constant during the whole flight mission, which is justified by the use of high-temperature superconductors to minimize electrical losses.

\subsubsection{Power converters}

In this concept, $\mathrm{AC} / \mathrm{DC}$ converters are employed to transform the alternating current coming from the generator into direct current, and DC/AC converters, whose purpose is to transform the direct current, coming from the line, into alternating current. Furthermore, since the electric engine and generator employed in this study are considered to be permanent magnet synchronous motors, three-phase alternating systems must be considered. At first instance, all the devices related to the control and regulation of electrical quantities (eg. Filters, voltage, and current regulators or controllers) are neglected. The component sizing is performed with the following assumptions: constant working temperature; the switching time is neglected; switching frequency is much larger than the output frequency; ripples caused by the alternating current are negligible; modulation is linear. As introduced by Vratny et al. [23] an estimate of the masses and efficiencies of the various components was carried out based on the value of conduction and switching losses, taking into account the limits on the voltage and current values that the single switching component can handle, as follows:

$$
\begin{gathered}
m_{\text {switch,tot }}=\left(6 \cdot n_{\text {parallel }} \cdot n_{\text {series }} \cdot m_{\text {switch }}\right) \cdot k_{\text {services }} \\
m_{\text {converter }}=m_{\text {switch,tot }} \cdot k_{\text {Cables }}
\end{gathered}
$$

Where $\mathrm{n}_{\text {par }}$ is the number of components in parallel, $\mathrm{n}_{\text {ser }}$ is the number of components in series, $\mathrm{m}_{\text {switch }}$ is the mass of a single switch, and $\mathrm{k}_{\text {services }}$ is the factor taking into account any additional equipment, equal to 2.5. Once The total mass of the switch $\mathrm{m}_{\text {switch,tot }}$ is obtained, the final mass of the inverter is obtained multiplying this for another factor $\mathrm{k}_{\text {cables }}$ taking into account the mass of the cable (set to 1.2). The evaluation of $\mathrm{n}_{\mathrm{par}}, \mathrm{n}_{\mathrm{ser}}$, and $\mathrm{m}_{\text {switch }}$ is taken from [23], here not reported for simplicity. In the same fashion, the efficiency is estimated with the following expression:

$$
\eta_{\text {converter }}=\frac{P_{\text {Out }}}{P_{\text {In }}}=\frac{P_{\text {Out }}}{P_{\text {Out }}+\sum_{n} P_{n} \cdot n_{\text {parallel }} \cdot n_{\text {series }}}
$$

Where $\mathrm{P}$ out is the power output of the converter $\mathrm{P} \mathrm{n}$ is the loss associated with a single switch, again modeled according to [23]. Once the maximum power and the maximum operating speed of the motor are known, it is possible to calculate the number of series/parallel components and retrieve the mass of the device. Regarding the efficiency, since the losses modeling is defined based on the input powers to the converter, the parameter is evaluated during the flight mission as a function of the specific operating condition.

\subsubsection{Batteries}

In the present work, the applicability of the batteries relies on two criteria, the specific energy $\mathrm{Wh} / \mathrm{Kg}$ and the specific power W/Kg. Recent technological advancements show an energy 
density still far from that necessary for the application in the field of aeronautical propulsion for medium-large scale aircraft. Nevertheless, a predictive study conducted by Kuhn and Sizmann [24] points to Lithium batteries as the most promising for increasing energy density. Therefore, the present work employs Lithium-ion batteries as possible technology to be implemented in mid-short terms. The battery energy density is assumed to be equal to $1200 \mathrm{Wh} / \mathrm{Kg}$ : this value is still not reached by the current technologies, nevertheless, it can be considered a good compromise for the development trends in this field [24].

By knowing the power to be handled, it is possible to derive the size and State of Charge (SOC) of the battery. Generally, this value should not fall below a certain level to avoid damages to the batteries (typically 10\%). The mass of the batteries is estimated starting from the power profile required by the drive shaft, the line efficiency, the energy density of the batteries, and the power supplied by the turboshaft to the electric generator during the flight phase. Therefore, the mass of the battery can be determined a priori considering a certain power supplied by the turboshaft during its operation. Here it is assumed that the energy demand from other devices besides those of the series hybrid line is not considered.

The batteries support all the power required during the Take-Off and Climb-Out phases, while the turboshaft works exclusively during the Cruise one. The average efficiency of all the components upstream to the battery is taken into account, while neglecting the battery's own efficiency. This approach is justified as a preliminary approach to quantifying the value of the weight. Furthermore, a verification of the SOC will allow to consider all the line efficiencies as a function of time and improve the mass evaluation. The following equation is applied for estimating the the required energy for a single flight phase:

$$
P_{\text {avg }} \cdot t=\rho_{\text {batt }} \cdot 3600 \cdot \mathrm{mbatt} \cdot \eta_{\text {batt } \rightarrow \mathrm{mot}} \cdot \mathrm{Po}
$$

Where $\mathrm{P}_{\text {avg }}$ is the average power used in the time interval $\mathrm{t}, \rho_{\text {batt }}$ (expressed in $\mathrm{Wh} / \mathrm{Kg}$ ) is the energy density, $m_{\text {batt }}$ is the mass of the battery, $\eta_{\text {batt } \rightarrow \text { mot }}$ is the efficiency of the line from the battery to the motor shaft, $\mathrm{P} \%$ is the percentage of energy used for the time interval considered. Firstly, the amount of energy required from the fan during each flight phase is evaluated to estimate $\mathrm{P} \%$, hence providing a gross estimation of the total energy to be stored in the battery. To do this, it is considered that the energy supplied by the turboshaft during the cruise phase goes to the engine and that the battery's energy must be increased by $10 \%$ to avoid having a completely flat battery at the end of the flight mission. The energy is therefore estimated as follows :

$$
E_{\text {batt }}=1.1 \cdot\left(E_{\text {rich }}-P_{A E} \cdot \eta_{\text {batt } \rightarrow \text { mot }} \cdot t_{\text {cruise }}\right)
$$

where $E_{b a t t}$ is the total energy of the battery, $E_{\text {rich }}$ is the energy required by the fan for the entire mission, $\mathrm{P}_{\mathrm{AE}}$ is the power supplied by the turboshaft, $\eta_{\text {batt } \rightarrow \text { mot }}$ is the efficiency of the line from the turboshaft to the motor shaft (excluding the battery), tcruise is the duration of the cruise phase. Once the total energy required for the batteries is known, also the energy required the contribution of the turboshaft during the cruise phase can be evaluated. The battery's SOC is estimated through an iterative cycle involving battery modeling with predictive assessments. This is sought by knowing the power required per phase and the battery's characteristics, following the approach reported in [12]. The batteries are represented as a voltage generator placed in series with three resistors representing the system's ohmic losses, concentration losses, and activation losses. Both the value of the resistors and the value of the voltage to the generator depend on the state of charge, which is why iteration is necessary. It is then possible to know the state of charge as a function of flight time and battery performance. Knowing the state of charge of the batteries, the mass can be evaluated, increasing its value when below the limit of $\mathrm{SOC}=10 \%$ at the end of the mission or vice versa. 


\subsection{Integration with flight mission data}

The flight mission characteristics are selected considering a proper reference flight for a short-mid range mission: flight data are recorded in terms of aircraft velocity, altitude, GPS coordinates, at given temporal steps starting from the Climb-Out phase. In this fashion, the whole flight mission can be described in terms of discrete points, hence the operating conditions during the overall duration. These inputs are used for the simulation of the conventional engines, obtaining the performance profile during the mission. Considering the flight mission data, Take-Off and Taxi/Idle phases are not included: in the present study only the former is modeled, since its high power demand, hence the impact on the battery design. The Taxi phase instead needs less power to be accomplished, even if its duration is longer than Take-Off. The impact of the Taxi phase on the minimum stored energy will be the object of future studies. The recorded flight data allows estimating the aerodynamic forces acting on the aircraft with a point-mass aerodynamic model. The drag forces are modeled considering the separate contributions of each part of the airframe for various configurations during the flight mission, following the strategy employed by Sun et al. [25]. An a priori evaluation of the required thrust is hence derived for each mission point and stored in a lookup table. This has been possible by considering for each flight point the velocity, the actual mass of the aircraft, and the angle of attack, thus establishing the overall drag acting on the aircraft. The integration between the flight mission data and the ESMS simulations is conducted within a python routine. At each time step according to the flight recorded data, the look-up table is queried to obtain the flight conditions and the related value of thrust $\left(\mathrm{T}_{\text {ref }}\right)$. The ESMS simulation is therefore initialized with this information and a dedicated loop varies the fuel flow until the calculated value of thrust equals $\mathrm{T}_{\text {ref. }}$ It should be noticed that in this procedure the contributions from the hybrid system are not present. Separate simulations have been conducted based on the profile of power, assuming that the electrically driven turbofan has to supply the same amount of thrust as the conventional engine being replaced.

\section{$3 \quad$ Test Case}

\subsection{Flight Mission and aircraft characteristics}

The selected flight mission corresponds to the flight route between Amsterdam Schipol (AMS) and the Firenze Peretola (FLR) airports, consisting of approximately 2 hours of flight. Flight records have been obtained from an open missions database available online [26]. Among the available aircraft operating in this scenario, the Embraer E190 is selected as testbed, since of its large diffusion for short-mid range missions: its main features are reported in [27]. In the present work, one of the conventional engines mounted on the E190 is replaced by the electrically driven fan already mentioned. The E190 is similar to the Bae 146-200, in terms of the number of seats and overall payload, where the latter was originally employed as a test-bed for the E-Fan-X demonstrator [28]. This experimental program adopted the same concept of hybrid-series propulsive system which is the objective of the study in the present work.

\subsection{Propulsive system}

The E190 in conventional configuration is equipped with the GE-CF34-10E turbofan [29]. This specific model is derived from the well-known CFM-56 engine, adopting the same turbofan double-shaft configuration and single annular combustion chamber (SAC). A lowpressure compressor (LPC) and a high-pressure compressor (HPC) are employed, both axial. 
The gas generator subsystem is completed with a high-pressure turbine (HPT), while the lowpressure shaft and the fan are driven by the power turbine (PT).

The turbo-shaft powering the electric generator in the hybrid system is the same proposed for the E-Fan-X concept and it is derived from the Rolls-Royce AE2100 turboprop [20]. This engine consists of a two-shaft architecture, that is the gas generator and the power turbine connected to the gearbox, then to the propeller in its original application. Here, this component is replaced by the electric motor which drives the fan and the inverter. The turboshaft employs an axial compressor, connected to the HPT. The combustion system consists of a single annular combustor, while the power generation is demanded to a power turbine (PT) for a maximum power output limited to around 3.5 MW for increasing the operational life. All the technical specifics used for both thermal engine modeling and electrical system (from [23]) defined in sections 2.3.2 and 2.3.3 are summarized in Table 1.

Table 1. Specifics for electric line (A.) and thermal engines (B.)

\begin{tabular}{|c|c|}
\hline \multicolumn{2}{|c|}{ A. } \\
\hline Electric Machine parameters & Value \\
\hline Airgap current density J & $130 \mathrm{kA} / \mathrm{m}$ \\
\hline Magnet flux density B & $2 \mathrm{~T}$ \\
\hline Shaft density $\rho_{\text {shaft }}$ & $7700 \mathrm{Kg} / \mathrm{m}^{3}$ \\
\hline Rotor density $\rho_{\text {rotor }}$ & $4800 \mathrm{Kg} / \mathrm{m}^{3}$ \\
\hline Stator density $\rho_{\text {stator }}$ & $7860 \mathrm{Kg} / \mathrm{m}^{3}$ \\
\hline Magnet density $\rho_{\text {magn }}$ & $6500 \mathrm{Kg} / \mathrm{m}^{3}$ \\
\hline Total efficiency & $95 \%$ \\
\hline
\end{tabular}

\begin{tabular}{|c|c|}
\hline \multicolumn{2}{|c|}{ B. } \\
\hline GE CF-34 & Value \\
\hline Nominal Thrust & $88 \mathrm{kN}$ \\
\hline Overall pressure ratio & $29: 1$ \\
\hline Bypass Ratio & 5.4 \\
\hline Overall engine weight (dry) & $1700 \mathrm{Kg}$ \\
\hline HPT + PT stages & $1+4$ \\
\hline FAN +LPC + HPC stages & $1+3+9$ \\
\hline Combustor type & SAC \\
\hline
\end{tabular}

\begin{tabular}{|c|c|}
\hline Power Converter parameters & Value \\
\hline Mass switch $m_{\text {switch }}$ & $330 \mathrm{~g}$ \\
\hline Switching energy transistor $E_{t r}$ & $195 \mathrm{~mJ}$ \\
\hline Switching energy diode $E_{d}$ & $53 \mathrm{~mJ}$ \\
\hline
\end{tabular}

\begin{tabular}{|c|c|}
\hline AE2100 turboshaft & Value \\
\hline Nominal power & $3.5 \mathrm{MW}$ \\
\hline Overall pressure ratio & $16.6: 1$ \\
\hline Air mass flow (SEA level) & $16.3 \mathrm{~kg} / \mathrm{s}$ \\
\hline Overall engine weight (dry) & $790 \mathrm{Kg}$ \\
\hline HPT + PT stages & $1+4$ \\
\hline Compressor stages & 14 \\
\hline Combustor type & SAC \\
\hline
\end{tabular}

\begin{tabular}{|c|c|}
\hline Battery parameters & Value \\
\hline Energy density $\rho_{\text {batt }}$ & $1200 \mathrm{Wh} / \mathrm{Kg}$ \\
\hline $\mathrm{SOC}(\mathrm{t}=0)$ & 1 \\
\hline
\end{tabular}

\section{$4 \quad$ Results}

From the thrust match obtained from the iterative process on fuel control, the power profile for the entire mission is obtained and shown in Figure 6. The maximum value assumed by the curve represents the design parameter for the HTS engine: this is reached during the Takeoff phase.

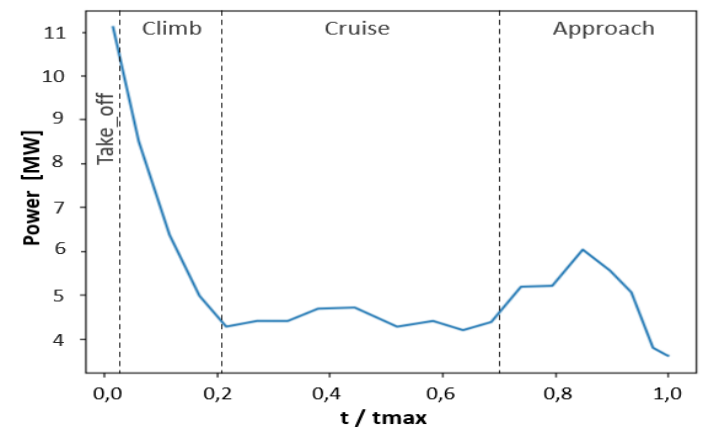

Fig.6. Low-pressure turbofan shaft power profile for the flight mission 
Once the power demand at the fan is evaluated, it is possible to estimate the power output at the battery including the turboshaft contribution. Its influence in the cruise phase is evident if considering the percentage of energy compared to the total energy demand per phase to the battery (Fig.7).

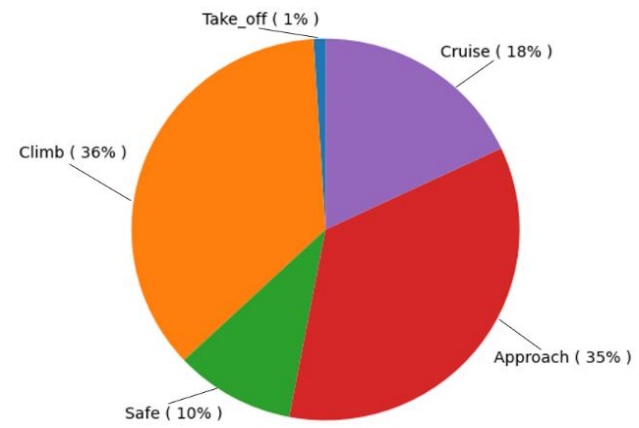

Fig.7. Total battery energy splitting in percent for the flight mission

In Figure 8, the estimated weight of each component within the hybrid system given by the simulation is reported. Taking into account that the modeling was carried out for state-ofthe-art technology, the results are in line with the power specific for the individual system [23]: from here, it is possible also to understand how devices handling the largest amount of power impact the configuration. The electric motor has to deal with more power than the generator considering the operation of the line. The same concept applies to the DC/AC converter which, in addition to the energy coming from the battery, must also handle the energy coming from the turboshaft. A similar assessment was also made for the battery pack, leading to an estimated weight of $\mathrm{m}_{\text {batt }}=6394 \mathrm{Kg}$.

B.
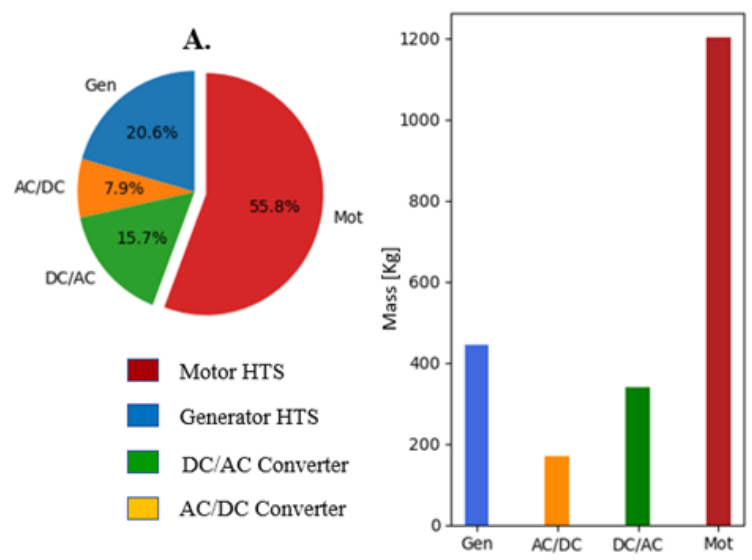

Fig.8. A. Percentage mass distribution of the system's electrical devices (excluding battery) B. Histogram of the weights of the system's electrical devices (excluding battery)

The impact in terms of the component mass is such that it is considered the weak point of the application, although a predictive energy density value has been adopted. Considering the current values [24], assuming an energy density value of $250 \mathrm{Wh} / \mathrm{Kg}$, a comparison can be made between batteries for the same application (Figure 9). This highlights the impracticality of the application under consideration for the current state of technology. 


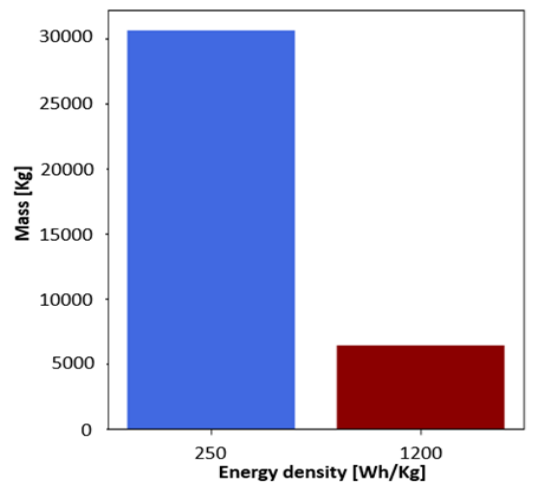

Fig.9. Comparison of weights between the current and predicted battery

In Figure 10 is reported the state of battery charge during the flight mission (red line). During the takeoff and climb phases, the state of charge decreases significantly due to the demand for power from the fan, which is only sustained by the battery. In the cruise phase, however, the trend is affected by the turboshaft energy contribution to the system. Nevertheless, this is not sufficient to completely sustain the fan power demand, which is why part of the energy will be taken from the battery. The slope of the curve in the final part of the mission (approach) tends to increase due to the absent energy contribution of the turboshaft. The performance of the battery is also shown (green line). A close dependence on the state of charge can be seen. When less work is required of the battery, it remains high. When the state of charge decreases more rapidly, there is a loss of efficiency. The reason for this can be found in the modeling and it is related to the fact that the efficiency is implicitly a function of the state of charge [23].

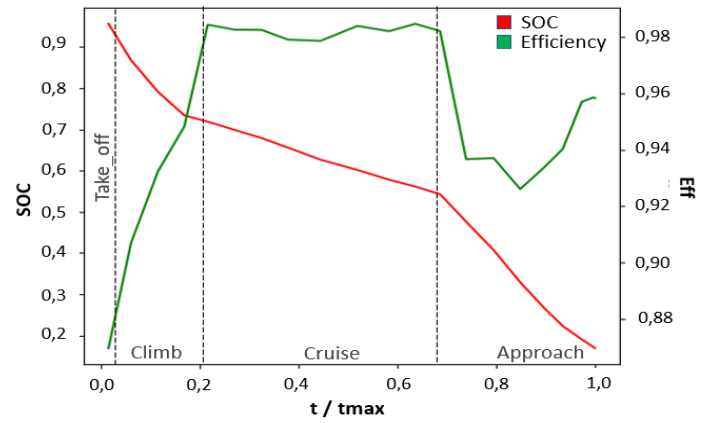

Fig.10. SOC and efficiency curves during the flight mission

The overall efficiency of the line from the turboshaft to the engine $\eta_{\text {turb } \rightarrow \text { mot }}$ and the overall efficiency of the line from the battery to the engine $\eta_{\text {batt } \rightarrow \text { mot }}$ are presented in Figure 10, while the respective definitions are given below:

$$
\begin{gathered}
\eta_{\text {turb } \rightarrow \text { mot }}=\eta_{\text {gen }} \cdot \eta_{A C / D C} \cdot \eta_{D C / A C} \cdot \eta_{\text {mot }} \\
\eta_{\text {batt } \rightarrow \text { mot }}=\eta_{\text {batt }} \cdot \eta_{D C / A C} \cdot \eta_{\text {mot }}
\end{gathered}
$$

The efficiency of a series system is given by the product of the efficiencies of the individual components, whereby efficiency $\eta_{\text {turb } \rightarrow \text { mot }}$ is given by the product of the efficiency of the generator $\eta_{\text {gen }}$, of the two power converters: the rectifier $\eta_{\mathrm{AC} / \mathrm{DC}}$, and the inverter $\eta_{\mathrm{DC} / \mathrm{AC}}$, while the last term is the efficiency of the HTS electric motor $\eta_{\text {mot }}$.

Similarly, efficiency $\eta_{\text {batt } \rightarrow \text { mot }}$ is the product of the efficiency of the battery pack $\eta_{\text {batt }}$, the inverter $\eta_{\mathrm{DC} / \mathrm{AC}}$ and the HTS electric motor $\eta_{\text {mot. }}$ In Figure 11 it can be seen that the efficiency 
$\eta_{\text {turb } \rightarrow \text { mot }}$ is lower than $\eta_{\text {batt } \rightarrow \text { mot }}$, as there is the rectifier to be considered, which entails a further loss of energy.

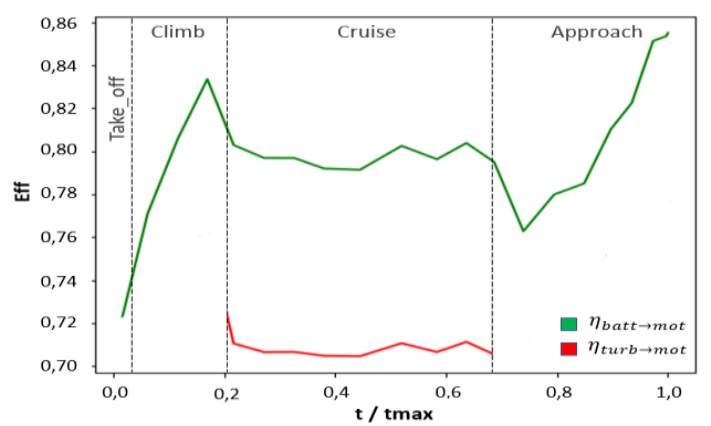

Fig.11. Line efficiency comparison during the flight mission

In Figure 12, the comparison in terms of weight between the two propulsion systems is reported. It can be noticed that the thermal propulsion system has a weight comparable to the sum of the components of the hybrid if the mass of the battery is neglected.

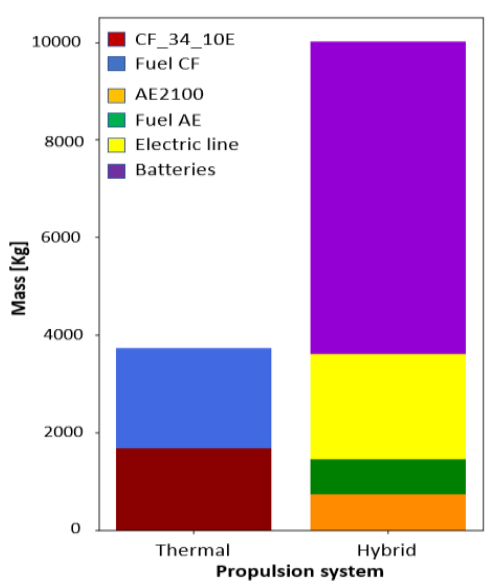

Fig.12. Weight comparison between the two proposed propulsion systems

An estimation of the total emission related to the flight mission is carried out in terms of $\mathrm{CO}_{2}$ and $\mathrm{NO}_{\mathrm{x}}$. The nitrogen oxide emissions are due to the presence of gaseous nitrogen in the air, which normally is not taking part in the combustion process itself. This chemical species is being activated by the high pressure and temperature present in the combustion chamber, therefore reacting with the oxygen largely available. In the present work, NOx production during the flight mission is evaluated through correlative approaches. Among the possible correlations available in the literature [30], the conventional engine has been evaluated thanks to the Boeing Fuel Flow method: it is based on a correction of the Emission Index (EI) at reference conditions, namely the ones of the LTO cycle. Thus, this method has been applied since the LTO cycle regarding the GE CF34 is known. Instead, considering that the AE2100 is a turboprop engine, the LTO cycle is not available. Thus, the estimation of the NOx emissions has been carried out with a correlation employing only the main thermodynamic parameters to derive a first severity parameter $\mathrm{S}_{\mathrm{NOx}}$ as follows :

$$
S_{\mathrm{NO}_{x}}=\left(\frac{\mathrm{P}_{3}}{2965}\right)^{0.4} \cdot \exp \left(\frac{T_{3}-826}{194}+\frac{6.29-100 \cdot \mathrm{WAR}}{53.2}\right)
$$

Where $\mathrm{P}_{3}$ and $\mathrm{T}_{3}$ are respectively the pressure and the temperature at the combustor inlet, and WAR is the water-to-air ratio of the inlet air. Therefore, the emission index is derived from 
the $\mathrm{S}_{\mathrm{NOx}}$, considering the combustion chamber type. According to [30], considering a SAC combustor, a corrective factor equal to 32 should be used, resulting in the following expression:

$$
E I_{N O x}=32 S_{N O x}
$$

The comparison between the conventional engine and hybrid engine emissions is reported in Figure 13: here the only cruise phase is considered. This choice aims to understand how the onboard generator will affect the $\mathrm{NO}_{\mathrm{x}}$ emissions, assuming that all the other flight phases are operated in full-electric mode, hence employing the hybrid system will be always beneficial. Furthermore, the evaluation of NOx emissions due to the stored energy in the batteries is not trivial and it is left to future works.

A.

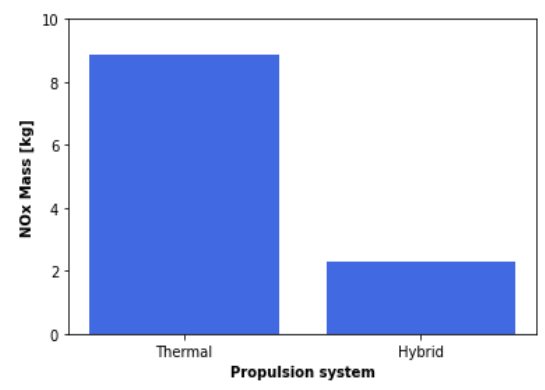

B.

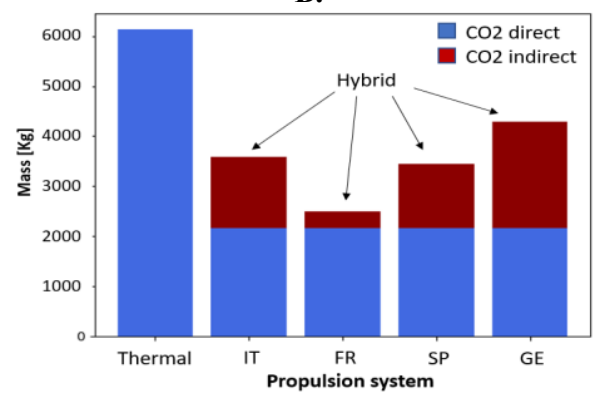

Fig.13. A. $\mathrm{NO}_{\mathrm{x}}$ emission B. $\mathrm{CO}_{2}$ emission comparison between Thermal and Hybrid propulsive systems during the flight mission for a single engine

The emission strictly related to the turboshaft included in the hybrid system, which it is worth recalling is activated only during the cruise, are $2.84 \mathrm{~kg}$, while a single CF34 engine during the same phase reaches $8.86 \mathrm{~kg}$. This substantial advantage is due to the use of the energy stored in the batteries for that phases which are usually critical in terms of NOx emission since the high power demand (i.e., high temperature and pressure) before reaching the nominal flight altitude. Nevertheless, this approach has been found oversimplified sometimes, since the factor 32 used in Equation 7 does not apply for all the SAC combustors [30], hence further investigations are required in this direction.

Concerning carbon dioxide, the estimation of the overall emission is directly computed within ESMS regarding all the turbomachines: their contribution is reported in Figure 13B again comparing both conventional and hybrid systems. Moreover, the $\mathrm{CO}_{2}$ emission for the whole flight mission is related also to the energy stored in the batteries. For this purpose, the plots are reporting two different contributions: the emissions related directly to the thermal engine are referred as $« \mathrm{CO}_{2}$ direct», while the $\mathrm{CO}_{2}$ given by the production of electric energy stored in the batteries is reported as $« \mathrm{CO}_{2}$ indirect». Also, this comparison is reported for different European countries, highlighting that the overall $\mathrm{CO}_{2}$ emission is largely affected depending on how the electric energy production takes place [31]. It is interesting also to notice that the mass of $\mathrm{CO}_{2}$ emitted at the cruise phase for the CF34 is $2388 \mathrm{~kg}$, while the emission related to the AE2 100 corresponds to $2163 \mathrm{~kg}$, hence very similar. It should be noticed that considering the emissions related to France, which shows a very low value of indirect $\mathrm{CO}_{2}$ emissions, thus almost negligible compared to the other scenarios, the overall $\mathrm{CO}_{2}$ emissions for the hybrid concept are circa one-third of the conventional engine. Indeed, this type of emission is related to the efficiency of the whole engine, so the adopted thermodynamic cycle. Keeping in mind this, it could be interesting in the future to investigate how the whole flight emissions could be affected if an ad hoc auxiliary unit is employed for the hybrid system. Lastly, it is interesting to estimate how the auxiliary components of the hybrid system are affecting the number of passengers allowed on board. In Figure 14A, the 
number of passengers of the conventional and hybrid configuration is reported: the latter is obtained considering a theoretical mass-to-passenger, knowing the overall payload and the number of passengers available on the E190 [27]. This value is the used to estimate the number of the passenger allowed in the hybrid configuration, once taken into account of the additional weight related to the electrical components, as well as the turboshaft. As expected, the hybrid configuration introduced additional weight at the expense of the payload, assuming not modifying the aircraft in any part. Also, in Figure $14 \mathrm{~B}$, the mass of $\mathrm{CO}_{2}$ per passenger is depicted again for the conventional and hybrid concepts: this latter refers to the best scenario among the possible of Figure 13B (France).

A.

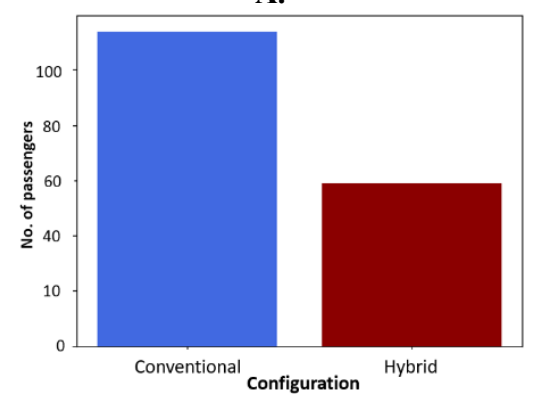

B.

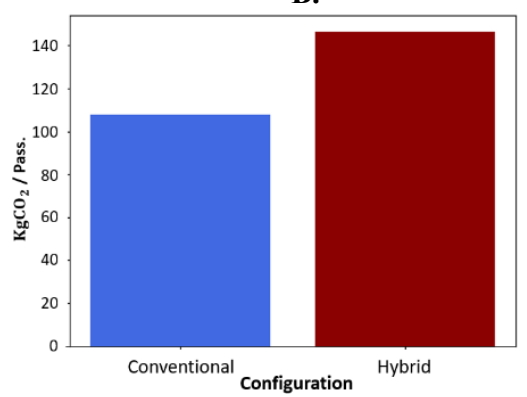

Fig.14. A. Total number of passengers $\mathbf{B} . \mathrm{CO}_{2}$ per passenger emission comparison between Conventional and Hybrid concept

Although the reduction of the overall $\mathrm{CO}_{2}$ emission due to the hybrid-series arrangement, the carbon footprint associated with each passenger is higher than the one with the conventional configuration. Again, this points out how only the development of lighter and more efficient components could justify the adoption of the investigated hybrid concept, at least under the carbon monoxide emissions point of view.

\section{$5 \quad$ Conclusions}

In this work, a hybrid-series propulsive system for short-mid range air civil transportation is investigated through low-order numerical simulations. This scenario is selected as the most suitable for this propulsion concept considering that the main challenge remains the additional weight introduced due to the electric components. The investigation involves the Embraer E190 as test-bed, where one of the conventional GE CF-34 engines is replaced with an electrically driven ducted fan. The energy required by this component is stored in batteries with an energy density equal to $1200 \mathrm{Wh} / \mathrm{kg}$. This value is crucial and it is assumed accordingly to the trends in this field. Otherhand, using the current state-of-the-art battery will avoid any advantage due to the hybrid concept. Moreover, a dedicated subsystem constituted of an inverter, AC/DC converter and an onboard turboshaft are present to support the batteries during Cruise conditions, which is the longest within the flight mission. This additional turbomachine works at constant load and it is derived by the Rolls-Royce AE2100 turboprop core engine. The flight mission is taken considering a 2 hours flight between Florence FLR and Amsterdam AMS as representative for a short-mid range flight route.

The results from the numerical simulations allow estimating the weight associated with the hybrid propulsive system, as well as a preliminary estimation of the $\mathrm{NO}_{\mathrm{X}}$ and $\mathrm{CO}_{2}$ emissions. As first, thanks to the recharge subsystem, the larger amount of energy stored in the batteries is not dedicated to the longest flight phase (i.e., Cruise conditions), but it is assigned to both Climb-Out and Approach phases (around the 35\% of the global amount), where a full electric flight mode is enabled. As expected, the bottleneck of the whole concept is represented by 
the mass of the batteries, since the weight of the hybrid drivetrain is comparable to the thermal engine being replaced.

Concerning $\mathrm{NO}_{\mathrm{X}}$ emissions, an estimation has been carried out through a correlative approach for both the thermal engine and the turboshaft of the hybrid system. The use of full-electric mode during the Take-Off and Climb-Out, which are associated with higher load conditions for the engines, allows reducing the overall $\mathrm{NO}_{\mathrm{x}}$ emissions during the flight. Also considering the only Cruise phase, the AE2 100 seems to produce lower $\mathrm{NO}_{\mathrm{X}}$ if compared to the GE CF34. However, since the previous technology level of the AE2100, lower nitrogen oxides are also related to a lower cycle efficiency. Eventually, a more accurate approach to estimate $\mathrm{NO}_{\mathrm{X}}$ emissions should be applied in the future to clarify this point. The last point regards $\mathrm{CO}_{2}$ emissions, which show another crucial point of this concept, that is how the energy stored in the battery is produced. Even if the worst-case scenario is taken into account, the overall emissions of the hybrid concept remain below the one associated with the standard thermal engine. Nevertheless, these results should be analyzed together with the actual implementation of the concept, which brings to a reduction of the available payload for a given aircraft. For this specific concept, it can be seen that the $\mathrm{kg}$ of $\mathrm{CO} 2$ per person is estimated as $146 \mathrm{~kg}$ in the hybrid concept, against the $108 \mathrm{~kg}$ due to the thermal engine (considering the best case scenario with the minimum amount of indirect $\mathrm{CO} 2$ ). In conclusion, this hybrid concept is showing overall lower emission with respect to the conventional configuration, but further improvement of the technologies employed are required before its real implementation.

\section{References}

1. Krein, A., \& Williams, G. (2012). Flightpath 2050: Europe's vision for aeronautics. Innovation for Sustainable Aviation in a Global Environment: Proceedings of the Sixth European Aeronautics Days, Madrid, 30.

2. Liu, Y., Sun, X., Sethi, V., Nalianda, D., Li, Y. G., \& Wang, L. (2017). Review of modern low emissions combustion technologies for aero gas turbine engines. Progress in Aerospace Sciences, 94, 12-45.

3. National Academies of Sciences, Engineering, and Medicine. (2016). Commercial aircraft propulsion and energy systems research: reducing global carbon emissions. National Academies Press.F. De Lillo, F. Cecconi, G. Lacorata, A. Vulpiani, EPL, 84 (2008)

4. Gohardani, A. S., Doulgeris, G., \& Singh, R. (2011). Challenges of future aircraft propulsion: A review of distributed propulsion technology and its potential application for the all electric commercial aircraft. Progress in Aerospace Sciences, 47(5), 369-391.

5. Hepperle, M. (2012). Electric flight-potential and limitations.

6. Zhang, X., Bowman, C. L., O'Connell, T. C., \& Haran, K. S. (2018). Large electric machines for aircraft electric propulsion. IET Electric Power Applications, 12(6), 767-779.

7. Zhang, X., \& Haran, K. S. (2016, September). High-specific-power electric machines for electrified transportation applications-technology options. In 2016 IEEE Energy Conversion Congress and Exposition (ECCE) (pp. 1-8). IEEE.

8. Driscoll, D. I. (2001, January). A review of superconducting motor technology development. In 2001 IEEE Power Engineering Society Winter Meeting. Conference Proceedings (Cat. No. 01CH37194) (Vol. 2, pp. 438-441). IEEE.

9. Jansen, R., Bowman, C., Jankovsky, A., Dyson, R., \& Felder, J. (2017). Overview of NASA electrified aircraft propulsion (EAP) research for large subsonic transports. In 53rd AIAA/SAE/ASEE Joint Propulsion Conference (p. 4701). 
10. Wroblewski, G. E., \& Ansell, P. J. (2019). Mission analysis and emissions for conventional and hybrid-electric commercial transport aircraft. Journal of Aircraft, 56(3), 1200-1213.

11. Aigner, B., Stumpf, E., Hinz, A., \& De Doncker, R. W. (2020). An Integrated Design Framework for Aircraft with Hybrid Electric Propulsion. In AIAA Scitech 2020 Forum (p. 1501).

12. Vratny, Patrick C., et al. "Battery pack modeling methods for universally-electric aircraft." 4th CEAS Air \& Space Conference. Linköping, Sweden: Linköping University Electronic Press, 2013.

13. Isikveren, A. T., Seitz, A., Vratny, P. C., Pornet, C., Plötner, K. O., \& Hornung, M. (2012, September). Conceptual studies of universally-electric systems architectures suitable for transport aircraft. In Deutscher Luft-und Raumfahrt Kongress. Berlin: DLRK.

14. Hornung, Mirko, et al. "Ce-liner-case study for emobility in air transportation." 2013 Aviation Technology, Integration, and Operations Conference. 2013.

15. Avanzini, G., de Angelis, E. L., \& Giulietti, F. (2016). Optimal performance and sizing of a battery-powered aircraft. Aerospace Science and Technology, 59, 132-144.

16. Carcasci, C., Marini, L., Morini, B., \& Porcelli, M. (2016). A new modular procedure for industrial plant simulations and its reliable implementation. Energy, 94, 380-390.

17. Poggiali, M., Gamannossi, A., Langone, L., \& Amerini, A. (2019, December). Civil aero-engine performance prediction using a low-order code and uncertainty quantification estimation. In AIP Conference Proceedings (Vol. 2191, No. 1, p. 020130).

18. Gamannossi, A., Bertini, D., Adolfo, D., \& Carcasci, C. (2017). Analysis of the GT26 single-shaft gas turbine performance and emissions. Energy Procedia, 126, 461-468.

19. ICAO Engine Emissions Databank, 2017. Available in Electronic Format from the EASA website.

20. Rolls-Royce AE 2100 datasheet: https://www.rolls-royce.com/products-andservices/defence/aerospace/transport-tanker-patrol-and-tactical/ae-2100

21. Pyrhonen, J., Jokinen, T., \& Hrabovcova, V. (2013). Design of rotating electrical machines. John Wiley \& Sons.

22. Rucker, J. E., Kirtley, J. L., \& McCoy, T. J. (2005, July). Design and analysis of a permanent magnet generator for naval applications. In IEEE Electric Ship Technologies Symposium, 2005. (pp. 451-458). IEEE.

23. Vratny, P. C., Forsbach, P., Seitz, A., \& Hornung, M. (2014, September). Investigation of universally electric propulsion systems for transport aircraft. In 29th Congress of the International Council of the Aeronautical Sciences (pp. 1-13).

24. Kuhn, H., \& Sizmann, A. (2012). Fundamental prerequisites for electric flying.

25. Sun, J., Hoekstra, J. M., \& Ellerbroek, J. (2018). Aircraft drag polar estimation based on a stochastic hierarchical model. In 8th International Conference on Research in Air Transportation.

26. Flight Aware Live flight tracking: https://www.flightaware.com

27. Embraer E190 datasheet: https://www.embraercommercialaviation.com/commercialjets/e190

28. Secretariat, I.C.A.O. (2019). Electric, hybrid, and hydrogen aircraft-state of play. Climate Change Mitigation: Technology and Operations, 124-130.

29. GE CF34 datasheet: https://www.geaviation.com/commercial/engines/cf34-engine 
30. Chandrasekaran, N., \& Guha, A. (2012). Study of prediction methods for NOx emission from turbofan engines. Journal of Propulsion and Power, 28(1), 170-180.

31. Caputo, A. (2018). Fattori di emissione atmosferica di gas a effetto serra e altri gas nel settore elettrico. ISPRA, Report, 280. 